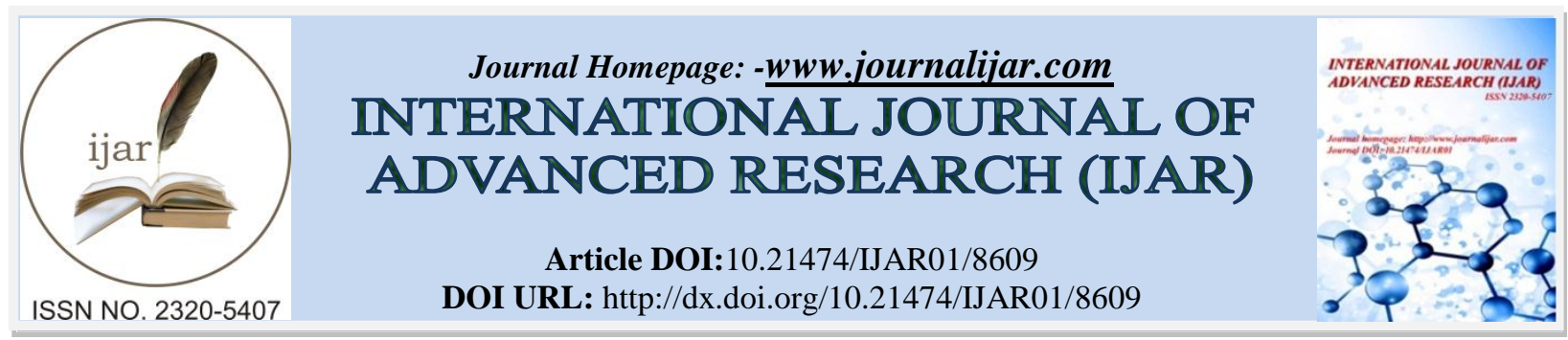

RESEARCH ARTICLE

\title{
A STUDY TO ASSESS THE EFFECTIVENESS OF VIDEO ASSISTED TEACHING (VAT)REGARDING KNOWLEDGE ON CARE OF CHILD WITH BREATHING DIFFICULTY AMONG THE CAREGIVERS OF CHILDREN ADMITTED IN A SELECTED PEDIATRIC HOSPITAL, BANGLORE.
}

Minu. S. R.

Assistant professor cum HOD Child Health Nursing department, Rama college of nursing, Mandhana, Kanpur.

\section{Manuscript Info}

Manuscript History

Received: 04 January 2018

Final Accepted: 06 February 2019

Published: March 2019

Key words:-

care givers, care of child, breathing difficulty, video assisted teaching.

\section{Abstract}

A pre experimental study was done to assess the effectiveness of video assisted teaching (VAT) regarding knowledge on care of child with breathing difficulty among the caregivers of children admitted in a selected pediatric hospital. The research approach adopted for the study was quantitative research approach and the research design was one group pre-test post- test design. Setting of the study was selected in Indira Gandhi Institute of Child Health Hospital, Banglore and the 60 samples were caregivers of children admitted in selected hospital selected by convenient sampling technique. Data collection was done by structured knowledge questionnaire. The video assisted teaching was given to the participants after pre-test knowledge assessment. Post test was conducted after 7 days and theresults revealed that among 60 care givers, level of knowledge on care of child in breathing difficulty, $35(58.33 \%)$ care givers had adequate knowledge and 25(41.67\%) care givers had moderate knowledge and none of the care givers had inadequate knowledge. The study concluded that video assisted teaching was very effective in improving knowledge regarding care of child in breathing difficulty among care givers of children admitted in hospitals.

Copy Right, IJAR, 2019,. All rights reserved.

\section{Introduction:-}

"Breathing ailments is here to stay - so we need to learn to manage it from an early age. No panic - just plan it"

Breathing difficulty can be a symptom of a variety of mild to serious disorders, diseases or conditions. Breathing difficulty is also called dyspnea, result from infection, inflammation, trauma, malignancy, airway obstruction and other abnormal processes. It can occur in any age group or population. Breathing difficulty can result from a relatively mild condition that is easy to resolve, to rather serious disorders affecting the respiratory or circulatory system. In children the main causes of breathing difficulty are common cold and cough, ALRI, asthma, bronchitis, pneumonia and foreign body aspiration.

In many areas the rise of respiratory diseases has been seen as communities adopt Western lifestyles and become urbanized. With the projected increase in the urban proportion of the world's population from $45 \%$ today to 59\% in 2025 , the increases in respiratory diseases are likely to continue over the next two decades. It is estimated that there 
may be an additional 100 million persons with respiratory diseases by 2025 . As children are more susceptible to these pollutants, breathing difficulty due to asthma and other respiratory ailments plays a major role in occupying them. So it significantly points out the need of proper education and research for the care givers of children suffering from breathing difficulty to reduce disease burden.

\section{Objectives of the study:}

1. To assess the pre test knowledge scores of care givers on care of child with breathing difficulty.

2. To determine the effectiveness of video assisted teaching on care of child with breathing difficulty among care givers.

3. To explore the association between post test level of knowledge on care of child with breathing difficulty and selected demographic variables of care givers

\section{Hypotheses}

1. $\mathrm{H}_{1}$ : There will be significant difference between the means of pre and post test knowledge scores of subjects exposed to video assisted teaching on care of child with breathing difficulty at 0.05 level of significance

2. H2 :There will be significant association between post test level of knowledge on care of child with breathing difficulty and selected demographic variables of care givers

\section{Materials And Methords Used:-}

Research approach:

Quantitative research approach.

\section{Research design:}

Pre experimental one group pre test post test research design.

\section{Setting of the study:}

Indira gandhi institute of child health hospital, bangalore

\section{Population:}

all the caregivers of children admitted in pediatric hospital.

\section{Sample:}

Caregivers of children admitted in selected departments of Indira gandhi institute of child health hospital.

\section{Sample size:}

60 caregivers of children admitted in selected departments of indra Gandhi institute of child health hospital

Sampling technique:

Non Probability convenient sampling technique

Variables:

Independent variable:

Video Assisted Teaching regarding care of child with breathing difficulty.

\section{Dependent variable:}

caregivers knowledge regarding care of child with breathing difficulty.

\section{Demographic variable:}

age, religion, gender, educational status, Occupation, income, place of residence, type of family, number of children, source of health information.

\section{Sampling criteria:}

Inclusion criteria:

Care givers of children who:

1. were available at the time of data collection in selected pediatric hospital .

2. were hospitalized for more than one week 


\section{Exclusion Criteria:}

Care givers who

1. were not willing to participate in the study.

2. Were not able to read and write Kannada or English

\section{Development and description of tools used in the study:}

The tool to assess the knowledge of caregivers regarding care of children in breathing difficulty was developed by the investigator by submitting to the review. Validity and reliability of the tool was checked.

The tool consists of 2 sections:

1. Demographic data of care givers.

2. Structured knowledge questionnaire on care of child with breathing difficulty.

\section{Scoring key and interpretation of the tool}

$\begin{array}{lcc}\text { Inadequate knowledge } & - & <50 \% \\ \text { Moderately adequate knowledge } & - & 50-75 \% \\ \text { Adequate knowledge } & - & >75 \%\end{array}$

Data collection procedure:

After a brief self-introduction of self and study, informed written consent from the care givers were obtained. The investigator established rapport with the care givers and assured them of confidentiality. Then the investigator after gaining confidence from the care giver collected the data in three phases.

Phase I: Selection of caregiver

Phase II:Pre test and administration of video assisted teaching

Phase III:post test after 1 week of video assisted teaching

\section{Plan for data analysis:}

The data obtained from 60 samples was analyzed by adopting the Descriptive statistics as frequency and percentage of samples, mean, mean percentage, standard deviation and inferential statistics as $t$ test, chi-square test was prepared in accordance with various characteristics under study and percentage analysis was found

\section{Data Analysis And Interpretation}

Section 1:

Description of demographic data of 60 care givers of children.

\section{Section 2:}

Pre-test knowledge scores of care givers of children regarding care of child with breathing difficulty

Table 1:-Frequency and percentage distribution of pre-test knowledge scores care givers on care of child with breathing difficulty.

\begin{tabular}{|l|l|l|l|}
\hline Knowledge level & Category & Respondents & Percentage \\
\cline { 3 - 4 } & & Frequency & 100 \\
\hline Inadequate & $<50 \%$ & 60 & 0 \\
\hline Moderate & $50-75 \%$ & 0 & 0 \\
\hline Adequate & $>75 \%$ & 0 & 100 \\
\hline Total & & 60 & $\mathbf{0}$ \\
\hline
\end{tabular}

Table-1 shows that, in pre-test, $100 \%$ of the care givers had only inadequate knowledge regarding the care of child with breathing difficulty.

\section{Section 3:}

Post-test knowledge scores of care givers of children regarding care of child with breathing difficulty. 
Table 2:-Frequency and percentage distribution of post-test knowledge score of care givers of children regarding the care of child with breathing difficulty.

\begin{tabular}{|l|l|l|l|}
\hline \multirow{2}{*}{ Knowledge level } & Category & Respondents & N=60 \\
\cline { 3 - 4 } & & Frequency & Percentage \\
\hline Inadequate & $<50 \%$ Score & 0 & 0 \\
\hline Moderate & $50-75 \%$ Score & 25 & 41.67 \\
\hline Adequate & $>75 \%$ Score & 35 & 58.33 \\
\hline Total & & 60 & 100 \\
\hline
\end{tabular}

\section{Section 4:}

Effectiveness of VAT by comparing pre and post test knowledge scores of care givers.

Table 3:-Comparison of pre-test and post-test knowledge scores of care givers of children on care of child with breathing difficulty

\begin{tabular}{|c|c|c|c|c|c|}
\hline & & & & & \\
\hline \multirow[t]{2}{*}{ Aspects } & \multirow[t]{2}{*}{ Max. Score } & \multicolumn{3}{|c|}{ Respondents } & \multirow[t]{2}{*}{ t-value } \\
\hline & & Mean & SD & Mean $(\%)$ & \\
\hline Pretest knowledge score & 34 & 0.018 & 3.776 & 0.054 & \multirow[t]{3}{*}{$45.5^{*}$} \\
\hline Posttest knowledge score & 34 & 25.133 & 1.995 & 73.921 & \\
\hline Enhancement & 34 & 25.115 & 1.781 & 73.867 & \\
\hline
\end{tabular}

$$
\text { *Significant at } 5 \% \text { level }
$$$$
[\mathrm{df}=60]
$$

NB: Table value at $\mathrm{df}=60$ and 0.05 level of significance is 2 .

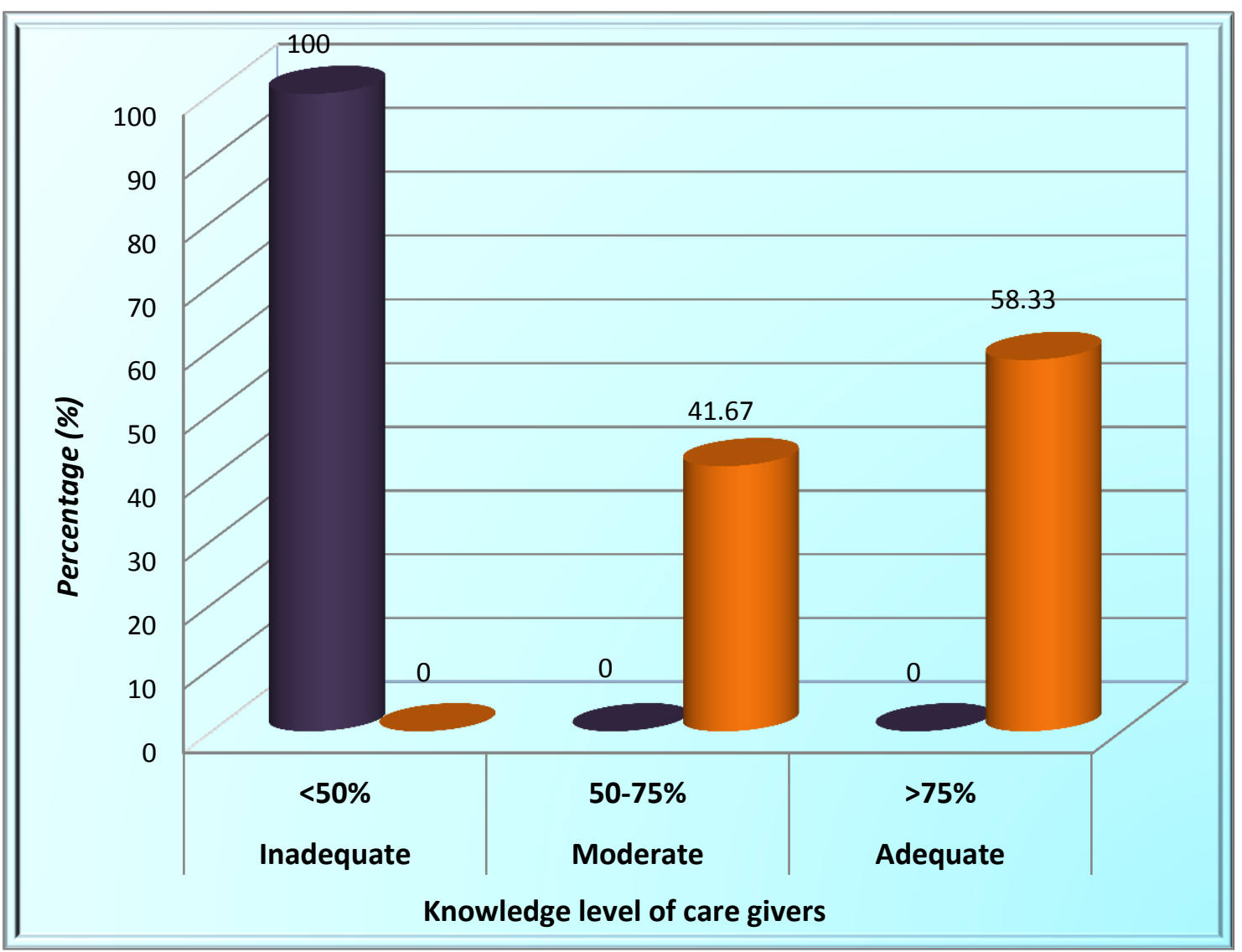

Figure 1:-Cylindrical graph showing over all pre-test and post-test level of knowledge scores of care givers 


\section{Section 4:}

Association of post test knowledge scores with selected demographic variables

There was no statistical significant association between post test scores and the selected demographic variables of care givers such as age, gender, religion, family income, , type of family, place of residence, educational status, occupation and sources of information with regard to knowledge on care of child with breathing difficulty. Hence $\mathrm{H}_{2}$ rejected as there was no association between post test knowledge and selected demographic variables.

\section{Discussion:-}

\section{Major Findings of the study:}

1. As per socio-demographic variables, the maximum care givers i.e $30(50 \%)$ belonged to the age group of 20-30 years, $20(33.33 \%$ ) were in the age group of $30-40$ years, and followed by $10(16.7 \%)$ were in the age group 40 50 years

2. With regard to religion of care givers the maximum number of care givers belonged to Hindu religion i.e. 32(53.33\%), Muslims were 16(26.67\%) followed by Christians i.e12(20\%).

3. With regard to place of residence $39(65 \%)$ care givers in the study was rural dwellers while urban were $21(35 \%)$.

4. Distribution of subjects according to the type of family maximum care givers included in the study i.e. 30(50\%) belonged to nuclear family and least number was from the group of single parent 4(6.6\%).

5. Pre-test knowledge score on care of child with breathing difficulty, almost all 60(100\%) had inadequate knowledge .None of the care givers had moderate or adequate knowledge regarding care of child with breathing difficulty

6. Post-test knowledge score on care of child with breathing difficulty $35(58.33 \%)$ care givers had adequate knowledge and 25(41.66\%) care givers had moderate knowledge and none of the care givers had inadequate knowledge.

7. On comparison of pre-test and Post-test knowledge score on care of the child with breathing difficulty among care givers revealed that the t- value 45.5 at $\mathrm{P} 0.05$ level is more than the table value $\mathrm{P}=2.01$, which showed that statistically high significance difference between the Pre-test and Post test level of knowledge. More over there is a significant enhancement in the post test knowledge scores of care givers after the VAT on care of the child with breathing difficulty.

8. The Chi square analysis showed that there was no statistically significant relationship between overall post test knowledge scores of care givers on care of the child with breathing difficulty with their selected demographic variables.

\section{Conclusion:-}

This study showed that care givers had an inadequate knowledge on breathing difficulty in children and video assisted teaching was very effective in improving the care givers level of knowledge regarding care of child with breathing difficulty. Hence the study points out to the fact that teaching strategies by nursing professionals can improve the knowledge of care givers in various health issues of children.

\section{Recommendations}

1. A similar study may be replicated with a control group.

2. Comparative study can be done with the same topic between educated and uneducated population.

3. A study can be conducted to assess the effectiveness of a different teaching protocol in terms of compliance, practice or skill and attitude of caregivers.

\section{Bibliography:-}

1. Wong L, Hokkenbery, Merlin I. Wong'snursing care of infants and children. $7^{\text {th }}$ ed. Texas: Mosby publication; 2009. p 1303-10

2. Marlow DR, Reeding BA. Textbook of paediatrics nursing. $6^{\text {th }}$ ed .NewDelhi: Reed Elsevier ; 2006. P 675-80.

3. World Health Organization. Respiratory tract infections:Available from: URL:http://www.who.int/research/en/

4. Sinha B, Nihar M. Pneumonia and epidemiology. Journal of epidemiology 2008; 14: 123-5

5. Ramkumar V, Aparajitha C, Respiratory disease burden in India. Journal of epidemiology. 2005;2(2):24-8

6. Carpenter DO, Ma J, Lessner L. Asthma and infectious respiratory disease. Journal of nursing studies .2008 Oct;1140:201-8. 
7. Deb SK.Acute respiratory disease survey in Tripura in case of children below five years of age: Journal of the Indian Medical association 2002 Apr; 96(4):111-6.

8. Environmental Pollution in India. The Hindu 2009 Oct 21;Sec.A:3 (col .10)

9. Veldhoven V \& Vermeer A. Children with asthma and physical exercise: effects of an exercise programme.2001. P: 15:360-370.

10. Balachandran A, Shivbalan SO, Thangavelu.S. chest physiotherapy in Paediatric Practice Kanchi Kamakoti Childs Trust Hospital, Chennai, India. 2007.p- 403-20.

11..Shivbalan S, Balasubramanian S, Anandnathan. K. what do Parents of Asthmatic Children know about Asthma? Indian Journal of chest disease allied science, 2005 April; 47 (2): 81-7.

12. Lal A, Kumar L, Malhotra S. Knowledge of Asthma Among Parents of Asthmatic Children, Indian Journal of Paediatrics, 1995 Jun; 32 (6): 649-55. 